\title{
Adubação fosfatada em soja: Potencialidades de diferentes fontes
}

\author{
Phosphate fertilization in soy: Potentiality from different sources \\ Fertilización con fosfato en la soja: Potencial de diferentes fuentes
}

Recebido: 12/04/2021 | Revisado: 19/04/2021 | Aceito: 21/04/2021 | Publicado: 07/05/2021

\author{
Daiane Almeida Genari \\ ORCID: https://orcid.org/0000-0003-1286-5055 \\ Universidade Paranaense, Brasil \\ E-mail: daiane.genari@edu.unipar.br \\ Dyovanna Palin \\ ORCID: https://orcid.org/0000-0002-9747-8718 \\ Universidade Paranaense, Brasil \\ E-mail: dyovannapalin@edu.unipar.br \\ Luis Hideki Takahara \\ ORCID: https://orcid.org/0000-0003-0953-5418 \\ Universidade Paranaense, Brasil \\ E-mail: 1.takahara@edu.unipar.br \\ João Paulo Francisco \\ ORCID: https://orcid.org/0000-0002-7173-4461 \\ Universidade Estadual de Maringá, Brasil \\ E-mail: jpfrancisco2@uem.br \\ Ana Daniela Lopes \\ ORCID: https://orcid.org/0000-0003-2027-5741 \\ Universidade Estadual de Maringá, Brasil \\ E-mail: anadanielalopes@prof.unipar.br
}

\begin{abstract}
Resumo
O objetivo deste trabalho foi avaliar os efeitos da adubação mineral convencional e organomineral sobre o crescimento e desenvolvimento de Glycine $\max$ (L.) Merril. O experimento foi conduzido em delineamento inteiramente casualizado, com dois tratamentos e nove repetições: adubação mineral com fósforo e potássio, além de adubação organomineral (BRT Organom ${ }^{\circledR}$ ). Decorridos 70 dias da semeadura avaliou-se o comprimento da raiz e parte aérea, número de nódulos, número de vagens, massa fresca e seca da raiz, massa fresca e seca da parte aérea, atributos químicos e respiração basal do solo. Após análises dos resultados verificou-se que não houve diferença significativa para as características comprimento de parte aérea, comprimento de raiz e massa fresca da raiz. Contudo, para as características número de nódulos, número de vagens, massa fresca e seca da parte aérea, massa seca da raiz, e respiração basal do solo, o tratamento de adubação organomineral superou, em média, os valores obtidos no tratamento com adubação mineral. Diante dos resultados obtidos neste trabalho, o uso de adubo organomineral pode suprir os nutrientes requeridos pela planta, em substituição à adubação mineral convencional, podendo ser eficiente no crescimento e desenvolvimento da soja além de consistir em uma estratégia sustentável para a produção.
\end{abstract}

Palavras-chave: Glycine max L.; Fósforo; Organomineral.

\begin{abstract}
The purpose of this paper was to evaluate the effects of the conventional mineral and the orgamineral fertilization on the growing and development of the Glycine $\max (\mathrm{L}$.) Merril. The experiment was conducted using completely randomized design with two treatments and nine repetitions, being them: Mineral fertilization with phosphor and potassium, and the organomineral fertilization (BRT Organom ${ }^{\circledR}$ ). In the 70 days of seeding, the length of the root and some of the aerial part, was evaluated, beside the number of nodules, number of pods, fresh and dry mass of the root, fresh and dry mass of the aerial part, chemical attributes and the basal respiration of the soil. To the variables: length of the aerial part, length of the root and fresh mass of the root, there was no significant difference between the treatments. However, the variable: number of nodules, number of pods, fresh and dry mass of the aerial part, dry mass of the root and soil's basal respiration. Surpassed in the plants fertilized by the organomineral's one, in average, the obtained values in the mineral's fertilization treatment. The obtained results in this work show that the use of organomineral's fertilizer could supply the nutrients requested by the plant, in substitution of the conventional mineral fertilization, being efficient in the growing and development of the soybean, and further consisting in a sustainable strategy to the production.
\end{abstract}

Keywords: Glycine max L.; Phosphor; Organomineral. 


\begin{abstract}
Resumen
El objetivo de este trabajo fue evaluar los efectos de la fertilización mineral convencional y organomineral sobre el crecimiento y desarrollo de Glycine $\max (\mathrm{L}$.) Merril. El experimento se realizó en un diseño completamente al azar, con dos tratamientos y nueve repeticiones: fertilización mineral con fósforo y potasio, además de fertilización organomineral (BRT Organom ${ }^{\circledR}$ ). A los 70 días de la siembra se evaluó el largo de la raíz y parte aérea, número de nódulos, número de vainas, masa fresca y seca de la raíz, masa fresca y seca de la parte aérea, atributos químicos y respiración basal del suelo. . Después de analizar los resultados, se encontró que no hubo diferencia significativa para las características de longitud de la parte aérea, longitud de la raíz y masa de raíz fresca. Sin embargo, para las características número de nódulos, número de vainas, masa fresca y seca de la parte aérea, masa seca de la raíz y respiración basal del suelo, el tratamiento de fertilización organomineral superó, en promedio, los valores obtenidos. en el tratamiento con fertilización mineral. A la vista de los resultados obtenidos en este trabajo, el uso de fertilizante organomineral puede suministrar los nutrientes requeridos por la planta, reemplazando la fertilización mineral convencional, pudiendo ser eficiente en el crecimiento y desarrollo de la soja además de ser una estrategia sustentable de producción.
\end{abstract}

Palabras clave: Glycine max L.; Fósforo; Organomineral.

\title{
1. Introdução
}

A soja é a principal proteína cultivada no Brasil e no mundo, e constitui o conjunto de atividades agrícolas de maior destaque no mercado global de commodities agropecuárias (Kirakuri \& Lazzarotto, 2014). Segundo informações oficiais, as exportações do agronegócio alcançaram US\$ 96,9 bilhões no ano de 2019 e o complexo soja representou 33,68\% deste total na safra de 2018/2019 (Brasil, 2020). Os estados com maior produção no ano-safra 2018/19 foram: Mato Grosso, responsável por cerca de 28,21\% da produção nacional; Rio Grande do Sul com 16,67\%; e Paraná com 14,12\% (Conab, 2019). Para a safra 2020/2021, a produção foi de 135,5 milhões de toneladas, representando um acréscimo de 8,6\% em relação ao ano agrícola anterior (Conab, 2021). Com produtividade média de $3523 \mathrm{~kg} \cdot \mathrm{ha}^{-1}$, a área cultivada com soja teve um salto de $4,1 \%$ em relação à safra anterior (Conab, 2021).

Segundo Sfredo (2008), a cultura da soja é largamente difundida no Brasil em distintas condições de clima. No entanto, trata-se de uma cultura bastante exigente quanto aos macronutrientes essenciais e, para que estes possam ser bem aproveitados, devem estar presentes no solo em quantidades suficientes e equilibradas, caso isso não ocorra, pode suceder em uma deficiente ou excessiva absorção destes (Sfredo, 2008). Conforme Vitti e Trevisan (2002), a soja necessita, além dos macronutrientes orgânicos $(\mathrm{C}, \mathrm{H}, \mathrm{O})$ fornecidos pela atmosfera, de nutrientes fornecidos pelo solo: $\mathrm{P}, \mathrm{K}, \mathrm{Ca}, \mathrm{Mg}, \mathrm{S}, \mathrm{B}, \mathrm{Cl}, \mathrm{Cu}$, Fe, Mn, Mo, Co e Zn e N, sendo N e K os mais extraídos pela cultura (Borkert et al., 1994).

Ainda que entre os três macronutrientes primários o P seja o menos extraído, em geral é o nutriente utilizado em maior quantidade, tendo por justificativa o baixo teor no solo e por sua baixa dinâmica nos solos tropicais (Vitti \& Trevisan, 2002). Segundo Sfredo (2008), o fósforo é um nutriente escasso na maioria dos solos brasileiros, pelo fato de apresentarem formações geológicas tipo Basalto, sedimentar e Caiuá, a exemplo dos solos paranaenses. Esta última originou solos de baixa fertilidade, alta acidez e de textura arenosa na camada arável, localizados principalmente na região Noroeste, correspondendo a 15\% das terras do Estado do Paraná, são solos oriundos da alteração do Arenito Caiuá (Fidalski, 1997).

Solos com as características encontradas no Arenito Caiuá tendem a apresentar deficiência em fósforo representando um fator restritivo para o crescimento das plantas, e promovendo o desenvolvimento de mecanismos bioquímicos e adaptativos para sustentarem a aquisição de fósforo inorgânico a fim de evitar a deficiência. A deficiência deste nutriente resulta em baixa produtividade e porte reduzido das plantas, em se tratando da soja, o mesmo reduz o potencial da espécie nos estádios iniciais reprodutivos pela redução de produção e maior abortamento de flores. O impacto da deficiência do nutriente na soja também se manifesta na formação de menor quantidade de vagens e maior abortamento das mesmas (Ventimiglia et al., 1999). Os nutrientes absorvidos pela soja são avaliados por meio da quantidade acumulada nas folhas e caules da planta, sendo crescente até alcançar o ponto de máximo acúmulo, de 75 dias. Após esse período, a absorção passa a ser decrescente, devido à translocação dos nutrientes para os grãos em formação (Embrapa, 1975). 
Por esta razão, a aplicação de fertilizantes orgânicos e organominerais pode conferir a melhoria dos atributos físicos e biológicos do solo, com a disponibilização gradativa de nutrientes (Abisolo, 2016). Na dinâmica do fósforo nos solos altamente intemperizados, como os Latossolos, predominam as formas inorgânicas ligadas à fração mineral com alta energia e as formas orgânicas estabilizadas física e quimicamente (Cross \& Schlesinger, 1995; Walker \& Syers, 1976).

No solo, o fósforo do solo é dividido em dois grandes grupos, fósforo inorgânico (Pi) e fósforo orgânico (Po), dependendo da natureza do composto a que está ligado. O fósforo orgânico pode constituir de 5 a $80 \%$ do fósforo total do solo e, nos solos tropicais, é fonte de fósforo às plantas e deve ser levado em consideração em estudos envolvendo a sua dinâmica e a biodisponibilidade (Rheinheimer \& Anghinoni, 2003), sendo originário dos resíduos vegetais adicionados ao solo, do tecido microbiano e dos produtos de sua decomposição (Conte et al., 2002; Martinazzo et al., 2007; D. S. Rheinheimer et al., 2000). Desta forma, após a transformação biológica dos resíduos animais e sua associação com minerais fontes é possível produzir fertilizantes organominerais granulados com alto teor de fósforo solúvel (Benites et al., 2010), cuja aplicação permite reduzir os altos custos com adubação essencialmente mineral e fornece nutrientes minerais e matéria orgânica (Tejada et al., 2005).

Diante do exposto, o objetivo deste trabalho foi avaliar duas fontes de fósforo por meio de adubação mineral convencional e organomineral sobre o crescimento e desenvolvimento da soja e seus efeitos sobre a melhoria das características do solo.

\section{Metodologia}

\subsection{Caracterização da área experimental e delineamento experimental}

O experimento foi conduzido em casa de vegetação no Campus 3 da Universidade Paranaense- Unipar, UmuaramaPR, nas coordenadas geográficas $53^{\circ} 17^{\prime} 37^{\prime \prime} \mathrm{W}$ e $23^{\circ} 45^{\prime} 52^{\prime \prime} \mathrm{S}$ e altitude de 442 metros. O ensaio foi realizado em delineamento inteiramente casualizado (DIC), com dois tratamentos e nove repetições, seguindo as premissas da metodologia científica apresentadas por Estrela (2018). Os tratamentos avaliados foram adubação mineral com fósforo $\left(\mathrm{P}_{2} \mathrm{O}_{5}\right)$ e a adubação organomineral (BRT Organom $®$ ), incorporados no solo antes do plantio. As unidades experimentais consistiram em tubos de PVC (policloreto de polivinila), com um metro de altura e $150 \mathrm{~mm}$ de diâmetro. A fonte de variação das adubações realizadas no experimento foi o elemento fósforo. Este, na forma de superfosfato simples®, apresenta de $16 \%$ a $18 \%$ de Pentóxido de difósforo $\left(\mathrm{P}_{2} \mathrm{O}_{5}\right)$ e de 18\% a 20\% de cálcio; na forma do organomineral BRT Organom ${ }^{\circledR}$ apresenta a formulação 01-18-00 (dos quais $8 \%$ do P disponibilizado encontra-se na forma solúvel em água e 10\% apresenta solubilidade gradual). Vale destacar que cada unidade experimental recebeu 1,44 g de adubação química com $\mathrm{KCl}$, incorporada no solo antes do plantio juntamente com a fonte fosfatada.

\subsection{Preparação e condução experimental}

Cada unidade experimental foi preenchida com 19,20 kg de solo previamente coletado em área pertencente com perfil classificado como Argissolo Vermelho Distrófico (V<50\%) (Embrapa, 2018) e localizado em área pertencente ao Hospital Veterinário da Unipar. Uma amostra representativa foi coletada e encaminhada para análise química e granulométrica (Tabela 1). Com base nos resultados da análise procedeu-se a calagem, sendo utilizadas $973,42 \mathrm{~kg} \cdot \mathrm{ha}^{-1}$ de calcário calcítico com PRNT 85, e adubação conforme Manual de Adubação e Calagem do Estado do Paraná e recomendação para a cultura (Pauletti \&

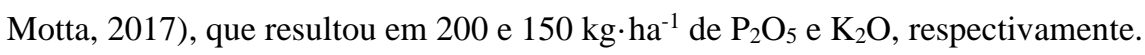


Tabela 1: Características químicas e granulométricas do solo. Valores do pH do solo em $\mathrm{CaCl} 2$ (pH), fósforo (P), zinco ( $\mathrm{Zn}$ ), matéria orgânica (M.O), potássio (K+), capacidade de troca catiônica (CTC) e saturação por bases (V).

\begin{tabular}{|c|c|c|c|c|c|c|c|c|c|}
\hline $\begin{array}{c}\mathrm{pH} \\
\mathrm{CaCl}_{2}\end{array}$ & $\begin{array}{c}\mathrm{P} \\
\mathrm{mg} \cdot \mathrm{dm}^{-3}\end{array}$ & $\begin{array}{l}\text { M.O. } \\
\mathrm{g} \cdot \mathrm{dm}^{-3}\end{array}$ & $\mathrm{Ca}$ & $\begin{array}{c}\mathrm{K} . \\
\text { nolc } \cdot \mathrm{dn}\end{array}$ & CTC & $\mathrm{V}$ & Areia & Silte & Argila \\
\hline 5,40 & 27,22 & 16,16 & 2,12 & 0,15 & 5,98 & 55,85 & 88,00 & 2,00 & 10,00 \\
\hline
\end{tabular}

Fonte: Laboratório Rural de Maringá (2018).

Em cada unidade experimental foram dispostas seis sementes de soja da variedade M6210, ciclo superprecoce de 115 dias de maturação, previamente inoculadas com inoculante turfoso Nitrosoy® contendo a bactéria Bradyrhizobium japonicum, conforme recomendação do fabricante. Após oito dias da emergência das plântulas realizou-se o desbaste mantendo duas plantas por unidade experimental.

\subsection{Análise dos parâmetros avaliados}

\subsubsection{Planta}

Aos 70 dias após a instalação do experimento, quando as plantas se apresentavam em estádio fenológico R5, procedeu-se a avaliação das seguintes características: comprimento da raiz (CR), comprimento parte aérea (CPA), número de nódulos (NNO), número de vagens (NV), massa fresca (MFR) e seca da raiz (MSR), massa fresca (MFPA) e seca da parte aérea (MSPA). O comprimento da raiz e da parte aérea foram aferidos com o auxílio de uma fita métrica de $150 \mathrm{~cm}$, enquanto para a massa fresca e seca foi utilizada balança semi-analítica de precisão. Para obtenção do número de nódulos, as raízes foram lavadas e os nódulos contados individualmente para cada sistema radicular. A massa seca foi obtida por meio de secagem em estufa com circulação e renovação de ar com ajuste de temperatura a $65^{\circ} \mathrm{C}$, até atingir peso constante.

\subsubsection{Solo}

Foram ainda avaliadas as características químicas do solo, a partir de nove subamostras, as quais foram encaminhadas para análise em laboratório especializado. Para avaliação da respiração basal do solo foram coletadas subamostras de solo, em hexaplicata, as quais foram acondicionadas em sacos plástico, identificados e mantidas sob refrigeração a $4^{\circ} \mathrm{C}$ até o momento da análise. A respiração basal do solo (RBS) foi determinada segundo Jenkinson e Powlson (1976), onde foram pesadas $30 \mathrm{~g}$ de amostra de solo de cada unidade experimental, e acondicionados em frasco de $100 \mathrm{~mL}$. Paralelamente, em um outro frasco (30 mL), juntamente foram adicionados $10 \mathrm{~mL}$ de hidróxido de sódio $(\mathrm{NaOH}) 1 \mathrm{~mol} \cdot \mathrm{L}^{-1}$. Ambos os frascos foram transferidos para recipientes de vidro hermeticamente fechados $(500 \mathrm{~mL})$. Como branco foram utilizados 3 frascos contendo somente $\mathrm{NaOH} 1 \mathrm{~mol} \cdot \mathrm{L}^{-}{ }^{1}$. As amostras foram incubadas por 8 dias em local escuro, com temperatura entre 25 a $28{ }^{\circ} \mathrm{C}$. Após a incubação, dos frascos que continham $\mathrm{NaOH}$ foram adicionados $2 \mathrm{~mL}$ de cloreto de bário $\left(\mathrm{BaCl}_{2}\right)$ a $10 \%$ e 3 gotas de fenolftaleína em solução alcoólica a 3\%. Na sequência procedeu-se a titulação das amostras com ácido clorídrico $\mathrm{HCl}$ $0,5 \mathrm{~mol} \cdot \mathrm{L}^{-1}$, sob agitação magnética, até a alteração de coloração rosa para incolor.

\subsection{Análise estatística dos dados}

Os dados, analisados de forma qualitativa, obtidos foram submetidos ao teste de normalidade de Shapiro-Wilk e após a confirmação da parametricidade foi aplicado o teste de Tukey com 5\% de probabilidade de erro. As análises foram realizadas por meio do programa estatístico SISVAR (Ferreira, 2011). 


\section{Resultados e Discussão}

\subsection{Planta}

Para as características comprimento de parte aérea, comprimento de raiz e massa fresca da raiz não houve diferença significativa $(\mathrm{p} \leq 0,05)$ entre os tratamentos. Contudo, para as características número de nódulos, número de vagens, massa fresca da parte aérea, massa seca da parte aérea e massa seca da raiz foi observada diferença estatística entre as adubações $(\mathrm{p} \leq 0,05)$.

\subsubsection{Número de Nódulos e vagens}

Na Figura 1 estão apresentados os resultados obtidos para as variáveis número de nódulos e número de vagens. O número médio de nódulos formados nas raízes das plantas adubadas com BRT Organom® foi superior $(29,33)$ ao encontrado nas plantas às quais foi disponibilizada apenas adubação química $(18,77)$, havendo um ganho de $56 \%$ na planta ao utilizar o organomineral (Figura 1A). Ao avaliar o número médio de vagens nos dois tratamentos verificou-se que BRT Organom® número superior $(29,88)$ quando comparado à adubação mineral $(18,83)(\mathrm{p} \leq 0,05)$ (Figura 1B), aumento da ordem de $60 \%$.

Figura 1. Número de nódulos (1A) presentes nas raízes e número de vagens encontrados em plantas em resposta a adubação organomineral e mineral.
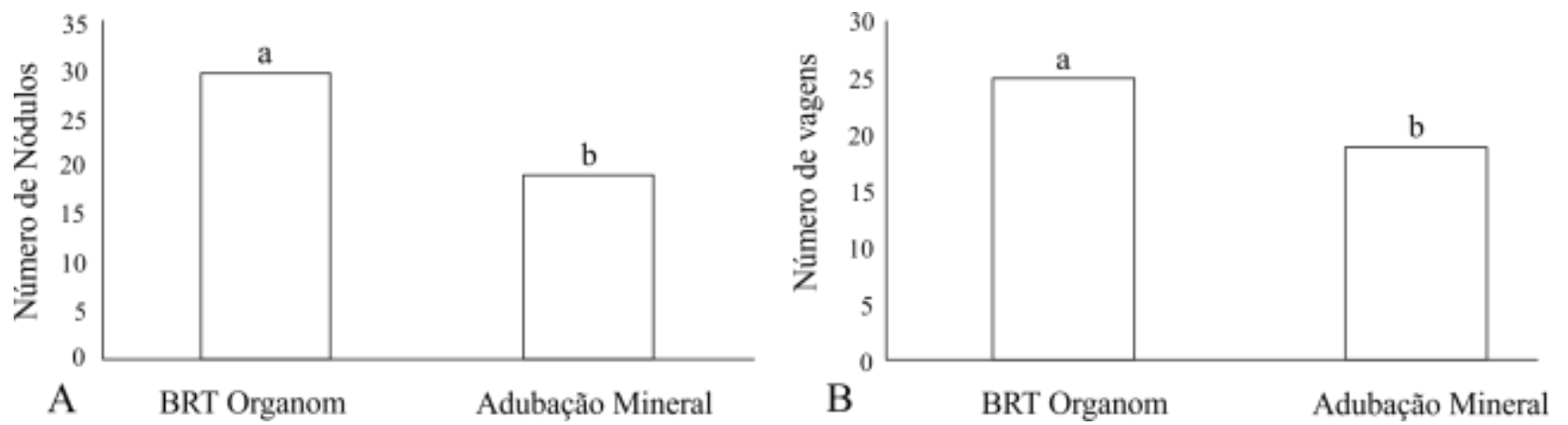

*Médias seguidas pela mesma letra não diferem entre si pelo teste Tukey a 5\% de probabilidade. Coeficiente de Variação=37,15\% (A); Coeficiente de Variação=18,52\% (B). Fonte: Autores.

Os resultados relativos ao número de nódulos podem estar associados ao maior aporte de matéria orgânica, resultante da aplicação dos resíduos orgânicos provenientes de vegetais ou dejetos animais (Benizri et al., 2001). Para Schloter et al. (2003) a sobrevivência de bactérias na rizosfera possui correlação positiva com o teor de matéria orgânica e de nitrogênio no solo, além de promover a sustentabilidade biológica e a produtividade nos ecossistemas.

Silva et al. (2019), ao avaliarem diferentes doses de adubo organomineral na cultura da soja, observaram que na dose de $750 \mathrm{~kg} \cdot \mathrm{ha}^{-1}$ houve um maior número de vagens em comparação às demais. Segundo Carvalho et al. (2011) a utilização da adubação com o resíduo orgânico (cama de frango) eleva o número de legumes por planta, porém em doses mais elevadas favorece o acamamento das plantas. Já no trabalho realizado por Junior et al. (2017), os autores observaram que resultados similares com aumento no número de vagens por planta. O que pode ter ocasionado essa maior produção no número de vagens, no tratamento com adubação do organomineral, foi a disponibilidade de fósforo para a planta durante dado o ciclo da cultura além da disponibilidade de nitrogênio, que são nutrientes essenciais para o crescimento e desenvolvimento da cultura, a falta de fósforo no solo poderia ter ocasionado uma baixa produtividade no número de vagens além de ocorrer o aborto de flores e reduzir a altura da planta. 


\subsection{Massa fresca e seca de parte área e massa seca de raiz}

A utilização do organomineral BRT Organom ${ }^{\circledR}$ favoreceu o aumento significativo $(p \leq 0,05)$ em relação à adubação mineral tanto da massa fresca $(31,30 \mathrm{~g}$ e $25,51 \mathrm{~g}$, respectivamente) (Figura $2 \mathrm{~A})$ quanto da massa seca da parte aérea $(6,87 \mathrm{~g}$ e $5,99 \mathrm{~g}$, respectivamente) (Figura 2B). Observou-se aumento significativo de massa seca da raiz no tratamento com o adubo organomineral. Os valores médios para a massa seca da raiz foram de 1,3 g nas plantas tratadas com BRT Organom® e de 0,9 g no tratamento com adubação mineral (Figura 3C), aumento de 44\% nas plantas adubadas com o organomineral.

Figura 2. Massa fresca de parte aérea (A), massa seca de parte aérea (B) e massa seca de raiz em plantas de soja como resposta à adubação organomineral e mineral.
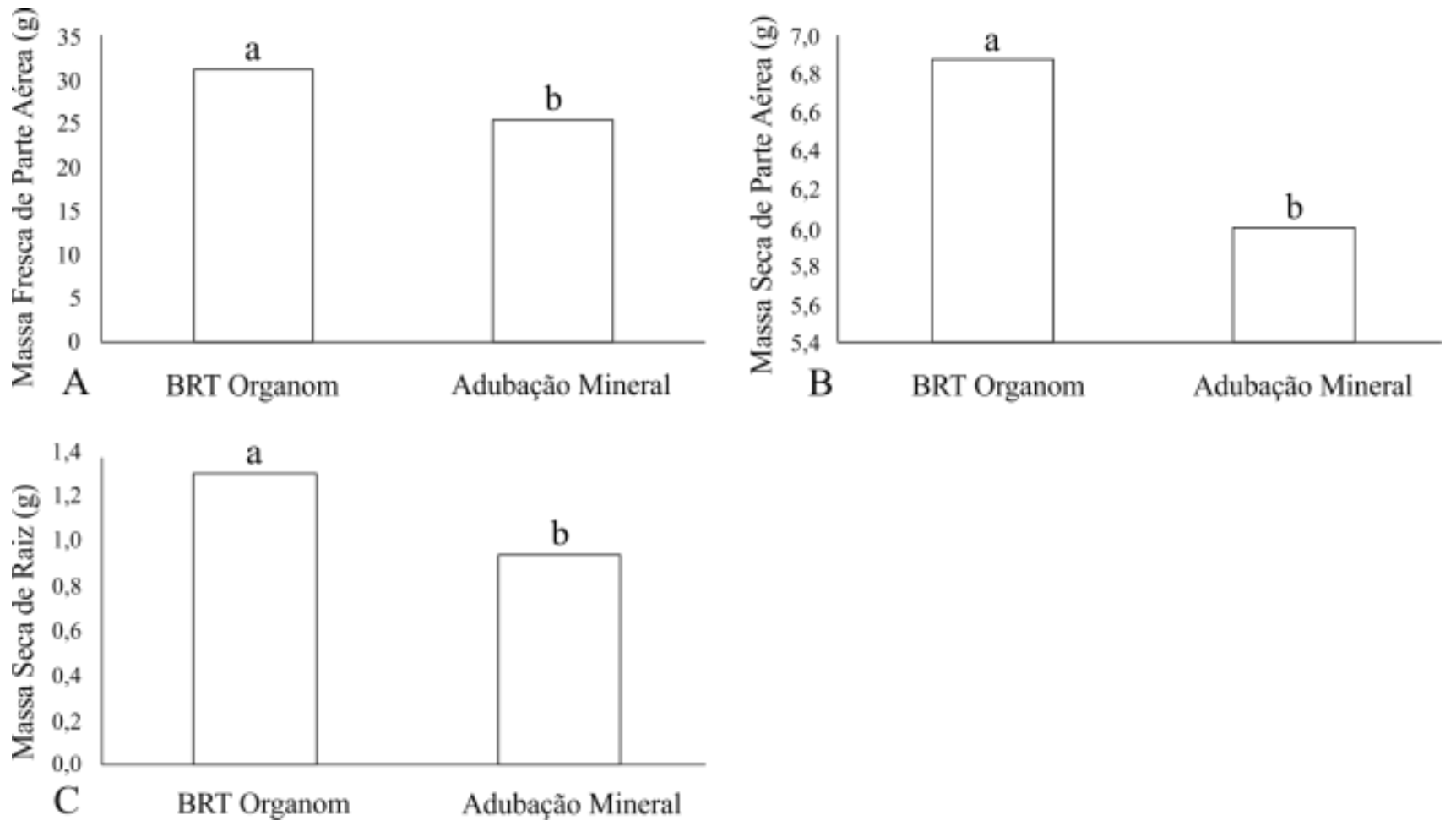

*Médias seguidas pela mesma letra não diferem entre si pelo teste Tukey a 5\% de probabilidade. Coeficientes de Variação=13,30\% (A); 13,48\% (B); 16,02 (C). Fonte: Autores.

Com a utilização do organomineral, se obteve um ganho de $23 \%$ e $15 \%$ para as características massa fresca (Figura 2A) e massa seca da parte aérea (Figura 2B), respectivamente. Segundo Bedin et al. (2003) o fósforo promove aumento na produção de fitomassa verde e seca da parte aérea, onde o aumento no fator capacidade de $\mathrm{P}$ do solo contribui para uma maior eficiência de utilização do nutriente, nivelando os efeitos de diferentes fontes de P no crescimento e produção da soja.

Conforme dados divulgados pelo fabricante, o BRT Organom tem como principal função promover maior equilíbrio químico, físico e biológico no sistema solo/planta; elevar o teor de matéria orgânica e a CTC do solo; aumentar a biota e a atividade biológica do solo; solubilizar e disponibilizar nutrientes; promover a descompactação do solo; reduzir a resistência à penetração das raízes; promover a melhoria da taxa de infiltração e da capacidade de retenção de água no solo; liberar gradativamente os nutrientes; evitar a salinização e acidificação; remineralizar o solo; reduzir a lixiviação e elevar o pH.

Segundo Bucher et al (2018), diante da característica química do fósforo, sua mobilidade e disponibilidade é baixa, fazendo com que os sinais morfológicos iniciais à sua carência se manifestem conforme mudanças no crescimento e arquitetura das raízes. 


\subsection{Solo}

\subsubsection{Análise química}

Na Tabela 2 está apresentada a avaliação química do solo ao final do experimento, esta possibilitou comparar a dinâmica dos nutrientes antes e após o cultivo e entre os tratamentos analisados. Na adubação mineral, verificou-se aumento na CTC do solo, elevando de 5,98 (Tabela 1) para 6,84\%. Notou-se redução da matéria orgânica, P e pH. Já para os nutrientes Ca e K foi verificada-se uma elevação (Tabela 2).

Tabela 2. Características químicas e granulométricas do solo. Valores do pH do solo em $\mathrm{CaCl} 2$ (pH), fósforo (P), zinco ( $\mathrm{Zn}$ ), matéria orgânica (M.O), potássio (K+), capacidade de troca catiônica (CTC) e saturação por bases (V) em resposta a Adubação Mineral.

\begin{tabular}{|c|c|c|c|c|c|c|c|c|c|}
\hline $\begin{array}{c}\mathrm{pH} \\
\mathrm{CaCl}_{2}\end{array}$ & $\begin{array}{c}\mathrm{P} \\
\mathrm{mg} \cdot \mathrm{dm}^{-3}\end{array}$ & $\begin{array}{l}\text { M.O. } \\
\mathrm{g} \cdot \mathrm{dm}^{-3}\end{array}$ & $\mathrm{Ca}$ & $\begin{array}{c}\mathrm{K} . \\
\text { holc. } \mathrm{dr}\end{array}$ & CTC & $\mathrm{V}$ & Areia & Silte & Argila \\
\hline 5,20 & 21,70 & 21,97 & 2,97 & 0,21 & 6,84 & 59,95 & 88,00 & 2,00 & 10,00 \\
\hline
\end{tabular}

Fonte: Laboratório Rural de Maringá (2020).

$\mathrm{Na}$ adubação com BRT Organom ${ }^{\circledR}$, houve uma discreta redução na CTC do solo $(5,98$ para 5,87\%) e na quantidade de matéria orgânica, passando de 16,16 (Tabela 1) para 16,80 g. $\mathrm{dm}^{-3}$. Ca e P apresentaram redução dos teores e o K mostrou um discreto aumento (Tabela 3). Segundo Santos et al. (2011) fontes orgânicas podem substituir por completo o P exigido pelas plantas, promovendo modificações na característica química do solo. Steiner et al. (2011) ao avaliarem os atributos químicos do solo em diferentes fontes de adubação observaram que a aplicação de dejeto suíno (adubação orgânica) ou complementada com fertilizante mineral (adubação organomineral) promoveu um aumento no teor de matéria orgânica ao comparar com a utilização de fertilizante mineral (adubação mineral), Tabela 3.

Tabela 3. Características químicas e granulométricas do solo. Valores do $\mathrm{pH}$ do solo em $\mathrm{CaCl} 2(\mathrm{pH})$, fósforo (P), zinco $(\mathrm{Zn})$, matéria orgânica (M.O), potássio (K), capacidade de troca catiônica (CTC) e saturação por bases (V) em resposta a BRT Organom

\begin{tabular}{|c|c|c|c|c|c|c|c|c|c|}
\hline $\mathrm{pH}$ & $\mathrm{P}$ & M.O. & $\mathrm{Ca}$ & K. & CTC & V & Areia & Silte & Argila \\
\hline $\mathrm{CaCl}_{2}$ & $\mathrm{mg} \cdot \mathrm{dm}^{-3}$ & $\mathrm{~g} \cdot \mathrm{dm}^{-3}$ & 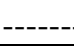 & lolc $\cdot \mathrm{dr}$ & -ב--- & & & & \\
\hline 5,10 & 19,97 & 16,80 & 2,40 & 0,19 & 5,87 & 58,29 & 88,00 & 2,00 & 10,00 \\
\hline
\end{tabular}

Fonte: Laboratório Rural de Maringá (2020).

\subsubsection{Respiração basal}

Plantas submetidas à adubação mineral convencional apresentaram menor $(\mathrm{p} \leq 0,05)$ respiração basal quando comparadas às plantas adubadas com o organomineral (Figura 3). 
Figura 3. Respiração Basal do solo em resposta a adubação organomineral e mineral.

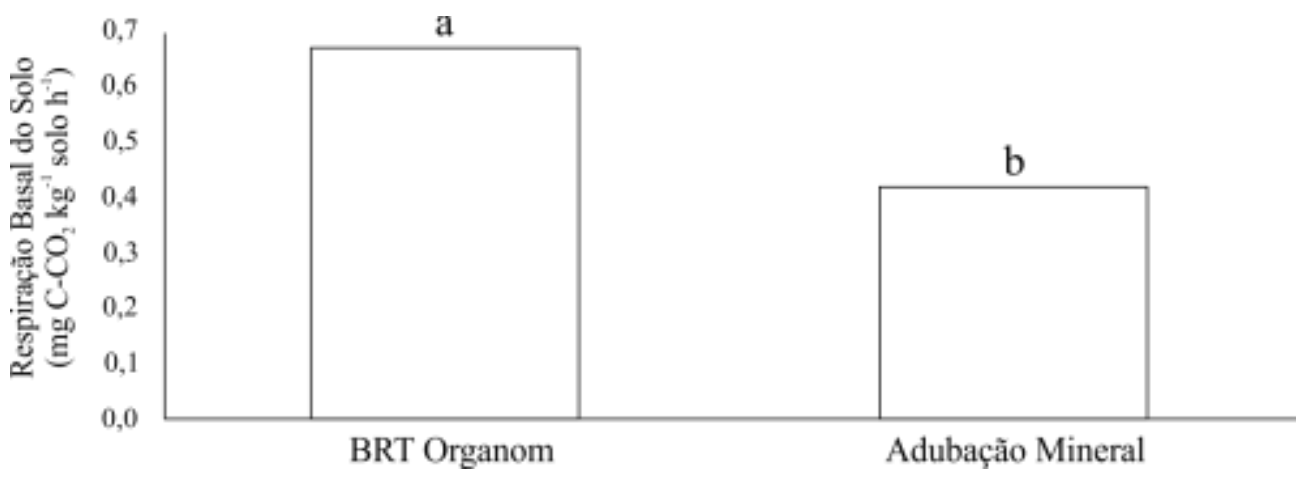

*Médias seguidas pela mesma letra não diferem entre si pelo teste Tukey a 5\% de probabilidade. Coeficiente de Variação=24,64\%. Fonte: Autores.

O fósforo e a matéria orgânica no solo são responsáveis por influenciar diretamente a atividade microbiológica do solo, uma vez que a matéria orgânica é fonte de carbono e energia para a biomassa microbiana (Silva, et al. 2016). No trabalho realizado por Boeira et al. (2009) com adubação mineral e lodo de esgoto na cultura da soja os autores verificaram que ao adicionar lodo de esgoto com base em critérios recomendados, o lodo demonstrou ser uma interessante fonte de matéria orgânica aos solos agrícolas de regiões tropicais, nos quais os teores de matéria orgânica geralmente são baixos, melhorando, com isso, a atividade microbiana do solo.

Sendo assim, a exemplo dos solos encontrados na região Noroeste do Paraná, como o Arenito Caiuá, a utilização de fontes de adubação que contenham maiores teores de matéria orgânica sugere uma excelente alternativa ao uso de adubos minerais.

\section{Conclusão}

O adubo organomineral BRT Organom $®$ demonstrou ser agronomicamente eficiente no crescimento e desenvolvimento da cultura da soja tanto quanto aos atributos químicos e físico do solo, comparado com a adubação mineral convencional.

Recomenda-se que trabalhos com aplicação sucessiva de adubo organomineral sejam realizadas, pois os mesmos, a longo prazo, podem potencializar os atributos químicos e físicos do solo, com resultados superiores aos observados neste trabalho.

\section{Referências}

Abisolo. (2016). Anuário brasileiro de tecnologia em nutrição vegetal. Abisolo.

Bedin, I., Furtini Neto, A. E., Resende, A. V., Faquin, V., Tokura, A. M., \& Santos, J. Z. L. (2003). Fertilizantes fosfatados e produção da soja em solos com diferentes capacidades tampão de fosfato. Revista Brasileira de Ciência Do Solo, 27(4), 639-646. https://doi.org/10.1590/s0100-06832003000400008

Benites, V. D. M., Correa, J. C., Faria, J., \& Menezes, S. (2010). Produção de fertilizante organomineral granulado a partir de dejetos de suínos e aves no Brasil. Worshop Internacional y Taller Nacional Valorización de Residuos, Oportunidad Para La Innovación, $2010,5$.

Benizri, E., Baudoin, E., \& Guckert, A. (2001). Root Colonization by Inoculated Plant Growth-Promoting Rhizobacteria. Biocontrol Science and Technology, 11(5), 557-574. https://doi.org/10.1080/09583150120076120

Boeira, R. C., Ligo, M. A. V., \& Maximiliano, V. C. B. (2009). Emissão de C-CO2 em Amostras de Latossolo Tratadas com Lodos de Esgoto. Boletim de Pesquisa e Desenvolvimento, 53, 1-20.

Borkert, C. M., Yorinori, J. T., \& Correa-Ferreira, B. S. (1994). Seja o doutor da sua soja. Potafos - Informações Agronômicas - No 66 - Encarte Técnico, 5 , $1-$ 17.

Brasil. (2020). Estatísticas de Comércio Exterior do Agronegócio Brasileiro. 2020. http://indicadores.agricultura.gov.br/agrostat/index.htm 
Carvalho, E. R., Rezende, P. M. de, Andrade, M. J. B. de, Passos, A. M. A. dos, \& Oliveira, J. A. (2011). Fertilizante mineral e resíduo orgânico sobre características agronômicas da soja e nutrientes no solo. Revista Ciência Agronômica, 42(4), 930-939. https://doi.org/10.1590/S1806-66902011000400015

Conab. (2019). Perspectivas para a agropecuária / Companhia Nacional de Abastecimento. Conab.

Conab. (2021). Acompanhamento da safra brasileira de grãos - v.7; oitavo levantamento. Conab.

Conte, E., Anghinoni, I., \& Rheinheimer, D. S. (2002). Fósforo da biomassa microbiana e atividade de fosfatase ácida após aplicação de fosfato em solo no sistema plantio direto. Revista Brasileira de Ciência Do Solo, 26(4), 925-930. https://doi.org/10.1590/S0100-06832002000400009

Cross, A. F., \& Schlesinger, W. H. (1995). A literature review and evaluation of the. Hedley fractionation: Applications to the biogeochemical cycle of soil phosphorus in natural ecosystems. Geoderma, 64(3-4), 197-214. https://doi.org/10.1016/0016-7061(94)00023-4

Embrapa. (1975). Ecologia, manejo e adubacao da soja. EMBRAPA CNPSo.

Embrapa. (2018). Sistema brasileiro de classificação de solos. In Centro Nacional de Pesquisa de Solos: Rio de Janeiro (5th ed.). Brasília, DF : Embrapa,.

Estrela, C. (2018). Metodologia científica: ciência, ensino, pesquisa. Artes Médicas.

Fidalski, J. (1997). Fertilidade do solo sob pastagens, lavouras anuais e permanentes na região noroeste do Paraná. Revista UNIMAR, 19(3), 853-861.

Junior, J. J. A., Smijanic, K. B. A., Matos, F. S. A., Justino, P. R. V., Silva, W. T. R., \& Cremonese, H. S. (2017). Utilização de adubação organomineral na cultura da soja. II Coloquio Estadual de Pesquisa Multidisciplinar, 2011-2016.

Kirakuri, M. H., \& Lazzarotto, J. J. (2014). O agronegócio da soja nos contextos mundial e brasileiro. Embrapa Soja.

Martinazzo, R., Santos, D. R. dos, Gatiboni, L. C., Brunetto, G., \& Kaminski, J. (2007). Fósforo microbiano do solo sob sistema plantio direto em resposta à adição de fosfato solúvel. Revista Brasileira de Ciência Do Solo, 31(3), 563-570. https://doi.org/10.1590/S0100-06832007000300016

Pauletti, V., \& Motta, A. C. V. (2017). Manual de adubação e calagem para o estado do Paraná. In Curitiba: Sociedade Brasileira de Ciência do Solo, Núcleo Estadual Paraná. ociedade Brasileira de Ciência do Solo, Núcleo Estadual Paraná.

Rheinheimer, D. S., Anghinoni, I., \& Conte, E. (2000). Fósforo da biomassa microbiana em solos sob diferentes sistemas de manejo. Revista Brasileira de Ciência Do Solo, 24(3), 589-597. https://doi.org/10.1590/S0100-06832000000300012

Rheinheimer, Danilo Santos, \& Anghinoni, I. (2003). Accumulation of Soil Organic Phosphorus by Soil Tillage and Cropping Systems Under Subtropical Conditions. Communications in Soil Science and Plant Analysis, 34(15-16), 2339-2354. https://doi.org/10.1081/CSS-120024068

Santos, D. H., Silva, M. de A., Tiritan, C. S., Foloni, J. S. S., \& Echer, F. R. (2011). Qualidade tecnológica da cana-de-açúcar sob adubação com torta de filtro enriquecida com fosfato solúvel. Revista Brasileira de Engenharia Agrícola e Ambiental, 15(5), 443-449. https://doi.org/10.1590/S1415-43662011000500002

Schloter, M., Dilly, O., \& Munch, J. . (2003). Indicators for evaluating soil quality. Agriculture, Ecosystems \& Environment, 98(1-3), 255-262. https://doi.org/10.1016/S0167-8809(03)00085-9

Sfredo, G. J. (2008). Soja no Brasil: calagem, adubação e nutrição mineral. Embrapa Soja.

Steiner, F., Costa, M. S. S. de M., Costa, L. A. de M., Pivetta, L. A., \& Castoldi, G. (2011). Atributos físicos do solo em diferentes sistemas de culturas e fontes de adubação. Global Science and Technology, 4(01), 16-28.

Tejada, M., Benitez, C., \& Gonzalez, J. L. (2005). Effects of Application of Two Organomineral Fertilizers on Nutrient Leaching Losses and Wheat Crop. Agronomy Journal, 97(3), 960-967. https://doi.org/10.2134/agronj2004.0092

Ventimiglia, L. A., Costa, J. A., Thomas, A. L., \& Pires, J. L. F. (1999). Potencial de rendimento da soja em razão da disponibilidade de fósforo no solo e dos espaçamentos. Pesquisa Agropecuária Brasileira, 34(2), 195-199. https://doi.org/10.1590/S0100-204X1999000200007

Vitti, G. C., \& Trevisan, W. (2002). Manejo de macro e micronutrientes para alta produtividade da soja. Potafos - Informações Agronômicas - Nº0 - Encarte Técnico, 16.

Walker, T. W., \& Syers, J. K. (1976). The fate of phosphorus during pedogenesis. Geoderma, 15(1), 1-19. https://doi.org/10.1016/0016-7061(76)90066-5 